\title{
Toward On-Site Closed Nuclear Cycles Not Requiring Deep Burial of Waste
}

\author{
T. Kenneth Fowler $\cdot$ Joonhong Ahn
}

Published online: 29 October 2009

(C) The Author(s) 2009. This article is published with open access at Springerlink.com

\begin{abstract}
We discuss a non-chemical means for onsite reprocessing of spent fuel from hybrid reactors such as LIFE and also deep burn fission reactors. Using a plasmabased Archimedes Filter of standard design, actinides could be removed in a few passes through the Filter to qualify as TRU waste that could be disposed of in a site like WIPP. An improved Filter is discussed that could reduce waste to 1 cubic meter per year, suitable for shallow burial.
\end{abstract}

Keywords Archimedes filter - Deep-burn reactors .

Nuclear fuel cycle $\cdot$ Geologic disposal $\cdot$ High-level wastes

This paper addresses the role of the nuclear option in meeting the California Energy Future goal of essentially zero carbon emission by 2050 . A $1-G W e$ reactor consumes about 1 metric ton of fissile fuel per year, turning it into fission product waste. There is also nuclear waste when a plant is decommissioned, and secondary waste incidental to plant operations. Here we address what has been the main focus of public attention, the steady stream of high-level waste (HLW) represented today by about 20 metric tons/ $\mathrm{GWe} / \mathrm{year}$ of light-water reactor (LWR) spent fuel consisting of the fission products, $\mathrm{Pu}$ and minor actinides (Np, $\mathrm{Am}$, and $\mathrm{Cm}$ ), all mixed with a large quantity of unburned uranium. We will focus on advanced "deep burn" reactors, such as the traveling wave reactor (TWR) being developed by TeraPower or the far-reaching LIFE fusion/fission hybrid concept at LLNL [1]. A neutron spectrum favorable

T. K. Fowler · J. Ahn $(\bowtie)$

Berkeley Nuclear Research Center, Department of Nuclear Engineering, University of California, Berkeley, CA, USA e-mail: ahn@nuc.berkeley.edu to breeding in deep burn reactors allows a burnup of uranium much higher than the 5\% typical of LWR's. However, our waste disposal concept may also have near-term applications to existing LWR's.

Suppose that a device co-located with a deep burn reactor could separate from the waste stream all actinides and selected fission products to be recycled and burned up inside the reactor, leaving about 1 ton/GWe/year of waste that would qualify as TRU waste, or even as Class $\mathrm{C}$ waste suitable for shallow burial. Just such a device is the Archimedes Filter initially aimed at removing actinides from waste at Hanford with considerable cost savings due to the reduced volume of HLW requiring deep geologic disposal. The Archimedes Demonstration Facility proved the concept at a throughput rate of 90 tons/year, more than needed, with $95 \%$ separation of heavy atoms.

Obstacles to similar ideas in the past, all involving chemical processing, have been cost, secondary waste, nuclear weapons proliferation concerns [2], and debates about what technical improvements would make any difference in repository regulations. The Archimedes Filter is a non-chemical approach with the potential for alleviating costs and reducing secondary waste, and as a "batch filter" that cannot separate pure plutonium it largely eliminates proliferation concerns. The desirable features of an Archimedes Filter are inherent in the concept, consisting of a Waste Injector and RF power to turn waste into a plasma flowing along magnetic field lines, followed by extraction of heavy ions by an electric field perpendicular to the magnetic field. More development work is needed on the Waste Injector, discussed below.

The regulatory issues require a sufficient change in technology to warrant a new appraisal of risks. While this is not entirely predictable in the context of the California Energy Future for 2050, we will use current NRC 
regulations as a guide to technological requirements, taking NRC Class $\mathrm{C}$ as a guide for shallow burial, and the TRU waste category that could be disposed of in a repository such as waste isolation pilot plant (WIPP). Our goal is to demonstrate the versatility of the Archimedes Filter to adapt to future guidelines (for example, stricter standards to take better account of environmental transport paths for isotopes such as ${ }^{129} \mathrm{I}$ or ${ }^{135} \mathrm{Cs}$ ).

On-site processing by an Archimedes Filter may have particular advantages for deep burn reactors, as an alternative to the idea that a deep burn reactor core like that for the TWR would be sealed and shipped to a customer who after decades of use ships it back full of waste. Deep burn reactors are breeders with a fast neutron component-from fission in TWR, from fusion in LIFE-that can burn up residual actinides and selected fission products that the Archimedes Filter would recycle through the reactor. Both TWR and LIFE can burn many fuel forms: LWR spent fuel, weapons $\mathrm{Pu}$, natural $\mathrm{U}$, etc. They thrive on depleted uranium as fuel, thus enabling profitable use of accumulated junk that will itself pose environmental hazards over time.

An example waste stream to be processed by the Archimedes Filter is shown in Table 1. We take 1 ton/year throughput, excluding secondary waste and decommissioning waste as noted above, and an unspecified amount of unburned uranium mixed with the fission products and $100 \mathrm{~kg}$ of $\mathrm{Pu}$ and minor actinides. The amount of unburned uranium, which varies with reactor scenarios, is mainly a cost issue, discussed below. To compare to NRC standards, we need the isotopic distribution of the $\mathrm{Pu}$ and minor actinides, which is case dependent [1]. Here we assume the same distribution as that for PWR's in Refs. [3] and [4], pro-rated for $100 \mathrm{~kg}$, to represent waste extracted from a deep burn reactor for recycling rather than delaying

Table 1 Example waste stream (excluding unburned $\mathrm{U}$ )

\begin{tabular}{|c|c|c|c|c|}
\hline \multicolumn{2}{|c|}{ Recyclable $\mathrm{Pu}\left(4 \%{ }^{241} \mathrm{Pu}\right)$} & $83 \mathrm{~kg} / \mathrm{year}$ & \multicolumn{2}{|c|}{$360,000 \mathrm{Ci}$} \\
\hline \multicolumn{2}{|c|}{ Minor actinides $\left(1.8 \times 10^{-4} \%{ }^{242} \mathrm{Cm}\right)$} & 17 kg/year & \multicolumn{2}{|c|}{$50,000 \mathrm{Ci}$} \\
\hline \multicolumn{2}{|c|}{ Total $\mathrm{Pu}$ and minor actinides } & $100 \mathrm{~kg} /$ year & \multicolumn{2}{|c|}{$410,000 \mathrm{Ci}$} \\
\hline \multicolumn{2}{|c|}{ Fission products, long-lived } & 83 kg/year & \multicolumn{2}{|c|}{$640 \mathrm{Ci}$} \\
\hline \multicolumn{2}{|c|}{ Activated ${ }^{14} \mathrm{C},{ }^{59} \mathrm{Ni}$} & $2 \mathrm{~kg} /$ year & \multicolumn{2}{|c|}{$150 \mathrm{Ci}$} \\
\hline \multicolumn{2}{|l|}{ Non-radioactive, other } & $782 \mathrm{~kg} /$ year & \multicolumn{2}{|l|}{-} \\
\hline \multicolumn{2}{|c|}{ Fission products etc. $1 / 2$ life $>30$ years } & $867 \mathrm{~kg} /$ year & \multicolumn{2}{|c|}{$790 \mathrm{Ci}$} \\
\hline \multicolumn{2}{|c|}{ Short half-life, ${ }^{90} \mathrm{Sr}(\mathrm{Y}),{ }^{137} \mathrm{Cs}\left({ }^{137 \mathrm{~m}} \mathrm{Ba}\right)$} & 33 kg/year & \multicolumn{2}{|c|}{$3.4 \times 10^{6} \mathrm{Ci}$} \\
\hline \multicolumn{2}{|c|}{ All fission products, activated material } & $900 \mathrm{~kg} /$ year & \multicolumn{2}{|c|}{$3.4 \times 10^{6} \mathrm{Ci}$} \\
\hline Class $\mathrm{C}$ accountable & TWR/LIFE example & \multicolumn{2}{|c|}{ le NRC standard } & Dilution \\
\hline Minor actinides & $0.06 \mathrm{Ci} / \mathrm{gm}$ of waste & \multicolumn{2}{|c|}{$100 \mathrm{nCi} / \mathrm{gm}$} & $6 \times 10^{5}$ \\
\hline${ }^{241} \mathrm{Pu}$ & $0.34 \mathrm{Ci} / \mathrm{gm}$ & \multicolumn{2}{|c|}{$3,500 \mathrm{nCi} / \mathrm{gm}$} & $10^{5}$ \\
\hline${ }^{242} \mathrm{Cm}$ & $1.0 \times 10^{-4} \mathrm{Ci} / \mathrm{gm}$ & \multicolumn{2}{|c|}{$20,000 \mathrm{nCi} / \mathrm{gm}$} & 5 \\
\hline
\end{tabular}

disposal to the reactor end-of-life. (By delaying disposal to allow fusion neutrons to burn up Pu, a LIFE engine could burn up $99.9 \%$ [1].)

Also shown in Table 1 is the current NRC standard for actinides in Class-C low level waste intended for shallow burial, and the Dilution factor required to meet the standards. While the waste volume is only of order $0.2 \mathrm{~m}^{3}$, we see that dilution alone is not an option. However, at the demonstrated collection efficiency of $95 \%$ for the original Standard Archimedes Filter, a mere fivefold dilution to $\approx 1 \mathrm{~m}^{3}$ together with only four passes through the Filter4 tons/year rate versus 90 tons/year demonstrated-would meet current NRC standards for TRU waste. Thus, recycling and burning actinides removed by the Archimedes Filter would yield waste in which only fission products would determine the waste category. Deposition codes developed by Archimedes Technology could confirm these conclusions.

Simply reducing actinides to the Class C standards required for TRU waste suitable for disposal at WIPP is probably a transformative change in waste management [5]. We already have real experience with such disposal options, unlike deep geologic disposal for HLW. On the technology side, producing only TRU waste does not require further development of the Standard Archimedes Filter except to adapt the Waste Injector to the reactor waste composition. While injection of a surrogate material to simulate Hanford waste was remarkably successful in the Archimedes Demonstration Facility, at the time Archimedes Technology ceased operations in 2006 problems had appeared for certain applications so that the Waste Injector remains a development item.

More speculative is the possibility of removing selected fission products to achieve the equivalent of Class $\mathrm{C}$ shallow burial for the entire waste stream-the long-term goal for pure fusion reactors [6]. The challenge is shown in Table 2 giving the fission product inventory in detail. Again fission product isotopic distributions are those for PWR waste [3, 4]. Differences between LIFE and LWR isotopic distributions are discussed in Ref. [1].

As is typical [1], initially most of the fission product radioactivity in Table 2 is in the short-lived isotopes ${ }^{90} \mathrm{Sr}$ (and very short-lived ${ }^{90} \mathrm{Y}$ ) and ${ }^{137} \mathrm{Cs}$ (and very short-lived ${ }^{137 \mathrm{~m}} \mathrm{Ba}$ ). Strontium and cesium could perhaps be separated by a Modified Archimedes Filter adapted to extract several batches of masses around selected atomic masses. One might then be able to recycle $\mathrm{Sr}$ and $\mathrm{Cs}$ to be transmuted inside the reactor. Or we could use the Modified Archimedes Filter only to reduce the mass of material requiring a cool off time on site. The total mass involved is about $60 \mathrm{~kg} /$ year including non-radioactive isotopes of $\mathrm{Sr}$ and $\mathrm{Cs}$ that the Filter could not separate from ${ }^{90} \mathrm{Sr}$ and ${ }^{137} \mathrm{Cs}$ (or residual long-lived ${ }^{135} \mathrm{Cs}$ ). 
Table 2 Selected isotopes

* $900 \mathrm{~kg}$ of fission products etc. isotopically distributed as in $12,725 \mathrm{gms} / \mathrm{bin}$ in Ref. [4]. Non-radioactive fission products use Ref. [3] to obtain mass ratios of all isotopes of a given radioactive element to the isotope listed in Ref. [4] plus omitted non-radioactive elements in ratio to ${ }^{99} \mathrm{Tc}$ in Ref. [4]

\begin{tabular}{|c|c|c|c|}
\hline Isotope & $\begin{array}{l}\text { Ref. } 4 \text { inventory } \\
\text { (per bin) }\end{array}$ & Activity & $\begin{array}{l}\text { Deep burn reactor } \\
\text { inventory }(\mathrm{kg})^{*}\end{array}$ \\
\hline \multicolumn{4}{|l|}{ Activated material } \\
\hline${ }^{14} \mathrm{C}$ & $0.065 \mathrm{gm}$ & $4.46 \mathrm{Ci} / \mathrm{gm}$ & $5 \times 10^{-3}$ \\
\hline${ }^{59} \mathrm{Ni}$ & 22 & $0.08 \mathrm{Ci} / \mathrm{gm}$ & 1.6 \\
\hline All activated mat'l & 22 & & 2 \\
\hline \multicolumn{4}{|l|}{ Fission products, short-lived } \\
\hline${ }^{90} \mathrm{Sr}\left({ }^{90} \mathrm{Y}\right)$ & 138 & $138 \mathrm{Ci} / \mathrm{gm}$ & 10 \\
\hline${ }^{137} \mathrm{Cs}\left({ }^{137}{ }^{\mathrm{m}} \mathrm{Ba}\right)$ & 330 & $86.8 \mathrm{Ci} / \mathrm{gm}$ & 23 \\
\hline${ }^{154,}{ }^{155} \mathrm{Eu}$ & 2 & $275 \mathrm{Ci} / \mathrm{gm}$ avg. & 0.1 \\
\hline Short-lived & 470 & & 33 \\
\hline \multicolumn{4}{|l|}{ Fission products, long-lived } \\
\hline${ }^{79} \mathrm{Se}$ & 9 & $0.004 \mathrm{Ci} / \mathrm{gm}$ & 0.6 \\
\hline${ }^{93} \mathrm{Zr}$ & 281 & $0.0025 \mathrm{Ci} / \mathrm{gm}$ & 19.9 \\
\hline${ }^{94} \mathrm{Nb}$ & 3.5 & $0.19 \mathrm{Ci} / \mathrm{gm}$ & 0.2 \\
\hline${ }^{99} \mathrm{Tc}$ & 416 & $0.017 \mathrm{Ci} / \mathrm{gm}$ & 29.4 \\
\hline${ }^{107} \mathrm{Pd}$ & 123 & $5 \times 10^{-4} \mathrm{Ci} / \mathrm{gm}$ & 8.7 \\
\hline${ }^{126} \mathrm{Sn}$ & 10.4 & $0.028 \mathrm{Ci} / \mathrm{gm}$ & 0.7 \\
\hline${ }^{129} \mathrm{I}$ & 96.9 & $1.8 \times 10^{-4} \mathrm{Ci} / \mathrm{gm}$ & 6.8 \\
\hline${ }^{135} \mathrm{Cs}$ & 235 & $0.0015 \mathrm{Ci} / \mathrm{gm}$ & 16.6 \\
\hline Long-lived & 1,175 & & 83 \\
\hline Other & 899 & - & 63 \\
\hline Non-radioactive & 10,159 & 0 & 719 \\
\hline All Mat'l except actinides & $12,725 \mathrm{gms}$ & & 900 \\
\hline
\end{tabular}

The main issue for shallow burial is the long-lived isotopes. Current standards for Class $\mathrm{C}$ shallow burial applicable when actinides meet the standards of Table 1 are listed in Table 3, using data from Table 2. Besides fission products, we include also ${ }^{14} \mathrm{C}$ and ${ }^{59} \mathrm{Ni}$, listed in NRC guidelines, as representative of activated material in the inventory of Ref. [4]. The listed Standard to meet shallow burial requirements is taken from Ref. [7] applying NRC guidelines, with some differences from NRC published numbers as indicated by the *

The volume in Table 3 is the Inventory divided by the Standard, giving the dilution volume per year required to meet the Standard. We see that diluting the waste to $1 \mathrm{~m}^{3}$, found sufficient to handle residual actinides after recycling, would also handle all fission products and activated material, if we also recycle ${ }^{94} \mathrm{Nb},{ }^{99} \mathrm{Tc}$ and ${ }^{126} \mathrm{Sn}$ to be burned up in a TWR or LIFE (and perhaps ${ }^{129} \mathrm{I}$ and ${ }^{135} \mathrm{Cs}$ which would not require further treatment under present regulations but might in the future: see "Appendix"). Per the table this requires three passes through a Modified Archimedes Filter with 95\% collection efficiency, versus four passes for the actinides. Just three or four passes to handle all actinides and relevant fission products is an order of magnitude fewer passes than is required for competitive schemes [5]. The actual efficiency may be greater than
Table 3 Class C standards for fission products, etc

\begin{tabular}{lllll}
\hline Isotope & $\begin{array}{l}\text { Inventory } \\
(\mathrm{Ci})\end{array}$ & $\begin{array}{l}\text { Standard } \\
\left(\mathrm{Ci} / \mathrm{m}^{3}\right)^{*}\end{array}$ & $\begin{array}{l}\text { Volume } \\
\left(\mathrm{m}^{3}\right)\end{array}$ & $\begin{array}{l}3 \text { passes } \\
\left(\mathrm{m}^{3}\right)\end{array}$ \\
\hline${ }^{14} \mathrm{C}$ & 22 & 80 & 0.3 & \\
${ }^{59} \mathrm{Ni}$ & 128 & 220 & 0.6 & \\
${ }^{79} \mathrm{Se}$ & 2.4 & 3 & 0.8 & \\
${ }^{93} \mathrm{Zr}$ & 49.6 & 200 & 0.25 & \\
${ }^{107} \mathrm{Pd}$ & 4.5 & TMSA & & \\
${ }^{129} \mathrm{I}$ & 6.8 & $30 *$ & 0.22 & \\
${ }^{135} \mathrm{Cs}$ & 3 & 8,400 & $<0.01$ & \\
& 216 & & & 0.02 \\
${ }^{94} \mathrm{Nb}$ & 38 & 0.2 & 190 & 0.3 \\
${ }^{99} \mathrm{Tc}$ & 500 & $0.2 *$ & 2,500 & 0.03 \\
${ }^{126} \mathrm{Sn}$ & 19.6 & $0.1 *$ & 196 & \\
& 774 & & &
\end{tabular}

* NRC standard, except ${ }^{99} \mathrm{Tc},{ }^{126} \mathrm{Sn},{ }^{129} \mathrm{I}$ from Tables 2 and 3, Ref. [7]

95\%, due to a lower plasma density, yielding even fewer passes.

We tentatively conclude that, for a Deep Burn Reactor with a modified Archimedes Filter, dilution of the waste in $\approx 1 \mathrm{~m}^{3}$ of packaging could reduce all waste to Class $\mathrm{C}$. 
Just $1 \mathrm{~m}^{3}$ of Class $\mathrm{C}$ waste per GWe per year would be much cheaper to dispose of than the equivalent HLW. The activity disposed of, equaling $216 \mathrm{Ci} / \mathrm{year} / \mathrm{GWe}$, is no more than the Class $\mathrm{C}$ waste already being disposed of by California utilities (for 2004-2008, average Class C shipped to depositories per year by all California utilities combined $=350$ cu.ft. $=10 \mathrm{~m}^{3}$ containing on average $700 \mathrm{Ci}$ total [8]). Reducing the waste volume to $1 \mathrm{~m}^{3} /$ year also might even open the option of on-site disposal of all of the waste, for some sites. With the possible exception of waste from on-site refabrication of recycled actinides and fission products, other waste disposal mainly concerns decommissioning. The non-chemical Archimedes Filter would be contaminated at decommissioning but should not produce a significant waste stream aside from secondary waste due to maintenance etc.

The required Modified Archimedes Filter might divide the 1 ton/year throughput into four or five mass batches: all actinides in one batch ( $\mathrm{U}, \mathrm{Pu}$ and minor actinides); $\mathrm{Sr}$ and $\mathrm{Cs}$ in other batches; $\mathrm{Nb}$, Tc and Sn in others; and the bulk containing everything else. For example, an optimized batch containing the $29.4 \mathrm{~kg} /$ year of ${ }^{99} \mathrm{Tc}$ from the Inventory of Table 2 might total $100 \mathrm{~kg} / \mathrm{year}$ including nonradioactive isotopes for a filter capable of extracting a mass batch over the range $95<\mathrm{A}<104$. Preliminary neutronics runs for the LIFE neutron spectrum applied to this batch indicate an $84 \%$ burnup of ${ }^{99} \mathrm{Tc}$ in 1 year despite a chain of transmutations that regenerate ${ }^{99} \mathrm{Tc}$ [9]. However, recycling $100 \mathrm{~kg} /$ year of fission products might consume too many neutrons, so that isotopic separation of ${ }^{99} \mathrm{Tc}$ is probably required. The LIFE spectrum would burn up $>99 \%$ of pure ${ }^{99} \mathrm{Tc}$ in 1 year [9].

The combination of a Modified Archimedes Filter and Atomic Vapor Laser Isotopic Separation (AVLIS) might serve to separate ${ }^{94} \mathrm{Nb},{ }^{99} \mathrm{Tc}$ and ${ }^{126} \mathrm{Sn}$. The Modified Archimedes Filter would separate out perhaps $100 \mathrm{~kg} /$ year as feed to a small AVLIS with optics modified to separate isotopes ${ }^{94} \mathrm{Nb},{ }^{99} \mathrm{Tc}$ and ${ }^{126} \mathrm{Sn}[10]$. While this AVLIS could perhaps be misused to separate $\mathrm{Pu}$, the throughput capacity of an AVLIS designed for on-site waste processing is small enough not to pose much proliferation threat. Setting aside the difficulty of stealing the highly radioactive core material, the Deep Burn Reactor inventory contains on average $<100 \mathrm{~kg}$ of Pu at any one time diluted by $900 \mathrm{~kg}$ of fission products, of which the AVLIS processor would only be capable of handling $10 \%(100 \mathrm{~kg})$ in a full year of diverted use, yielding then at most $10 \% \times 100 \mathrm{~kg}=10 \mathrm{~kg}$ of Pu, comparable to the IAEA Significant Quantity of $8 \mathrm{~kg}$. Thus, an acceptable system might be a modified multi-stage Archimedes Filter that separates actinides down to Class C by four passes through the Filter and which also separates a small quantity of selected fission products to be processed by the small AVLIS, thus allowing recycling of both residual actinide fuel and the worst fission product isotopes. Another isotopic separator developed at LLNL is the Solitron that might be less prone to proliferation risks if its throughput capacity could be increased sufficiently for the waste management application [11].

Thus, we are led to two scenarios shown in Figs. 1 and 2. Both would produce waste at decommissioning and a steady waste stream with classification depending on the type of Archimedes Filter employed. In Fig. 1 a few passes of 1 ton of waste through a Standard Archimedes Filter of the type already developed reduces the actinide content to Class C standards, giving 1 ton/year waste that might qualify as TRU waste. In Fig. 2 a multi-stage Modified Archimedes Filter together with a small AVLIS might additionally recycle selected fission products to yield only
Fig. 1 1-GWe deep burn reactor with standard Archimedes filter. See also Table 1

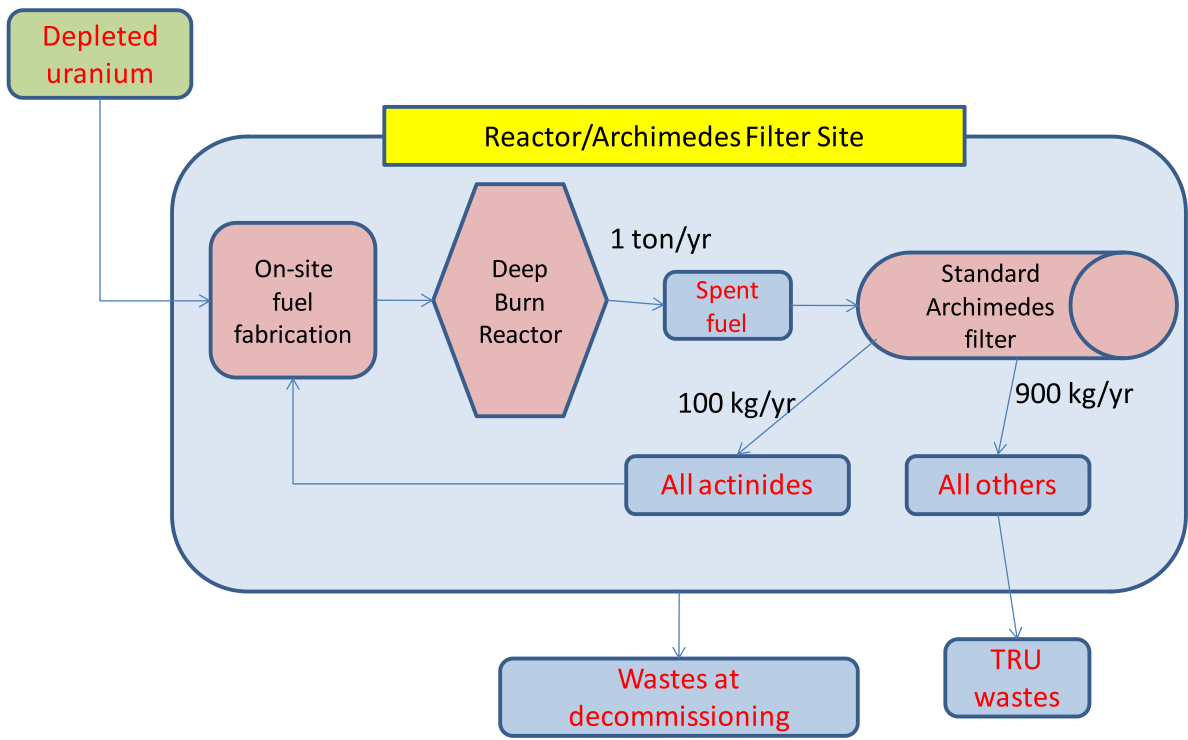


Fig. 21 GWe deep burn reactor with modified Archimedes filter

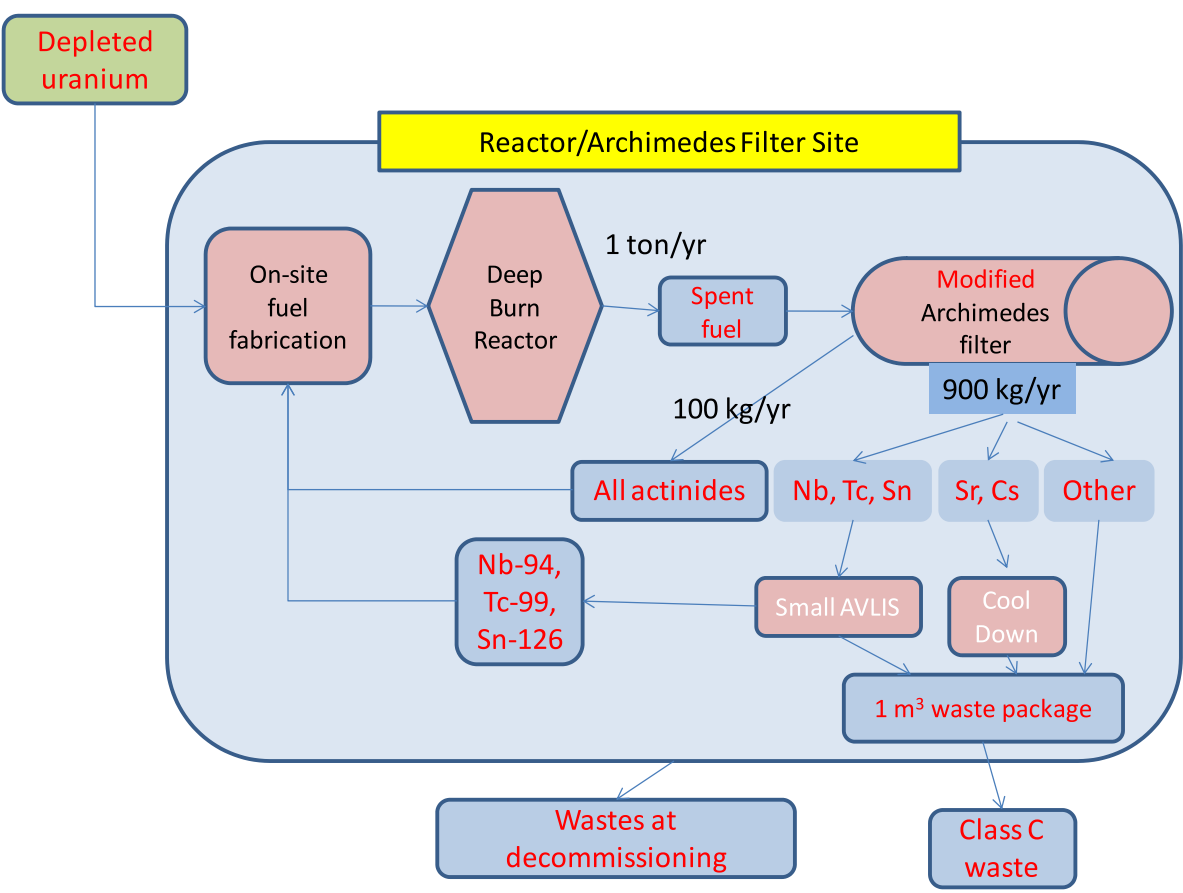

Class $\mathrm{C}$ waste suitable for shallow burial. Non-optimized example parameters for a Modified Archimedes Filter are given in the "Appendix".

As noted above, an important development problem not fully solved when Archimedes Technology ceased operations is the Waste Injector. As in other plasma applications, it is actually the pre-existing plasma that ionizes new material injected into the plasma, the energy being supplied by the RF. This is a feasibility question, not a question of power requirements, since the RF power required to maintain the temperature against radiation (acceptable, at most a few MW) dwarfs the ionization and injection power. Any form of injection that adequately exposes new material to the plasma will do - for example, vapor used in the Archimedes Demo, or tiny "pellets" such as powder produced by pulverization of solids. Material injection into plasmas is a research topic of wide interest for all forms of plasma processing.

To estimate costs, we extrapolate the Archimedes Technology cost estimate for the Hanford application giving about $\$ 4 \mathrm{M} /$ ton of throughput, or $\$ 0.1 \mathrm{M} /$ ton amortized over 40 years. This includes the cost of the Waste Injector and the cost of RF power, mainly the power to sustain a highly radiative low temperature plasma, based on actual experience in the Archimedes Demo. This cost is to be compared with about $\$ 1.5 \mathrm{M} /$ ton to dispose of HLW at a site like Yucca Mountain (\$90 B total to store 63,000 tons) and similar costs in Sweden and Japan. The feasibility and cost of on-site fabrication of recycled material, for example as TRISO, requires more study, but we note that $\approx 100 \mathrm{~kg} /$ year throughput is comparable to TRISO facilities at Babcock and Wilcox [12]. A best result might reduce all waste disposal to lowcost shallow burial.

The actual cost of the Archimedes Facility will depend on the number of passes required and the throughput of unburned uranium mixed with the fission products. This is only a reprocessing cost issue, not a disposal issue. The extreme example would be applying the scenario of Fig. 1 to an LWR, with 20 metric tons/year throughput. The actual number for deep burn reactors depends on design. Based on earlier TWR scenarios and LIFE scenarios midway through a 50 year burn, the upper limit is about 1 ton/ year of unburned uranium (with recycling giving the opportunity to reclad neutron-damaged fuel assemblies), thus doubling the throughput. Scenarios optimized for waste management could probably reduce this considerably.

Finally, it may indeed make sense to apply the nearterm scenario of Fig. 1 to on-site processing of LWR spent fuel. An important difference from deep burn breeders is how to maintain enrichment for the nonbreeding LWR. (A TWR also requires enrichment, but only once, to initiate breeding: LIFE does not require enrichment.) One could perhaps recycle the unburned uranium and other actinides in LWR spent fuel on site, augmented by externally enriched fuel; or ship the actinides to an enrichment plant. As noted above, a higher throughput for the LWR increases the cost of the Archimedes Filter and fuel refabrication, though we note that several countries, using chemical methods, have already pursued development to recycle LWR fuel. 
More study is needed to assess the technological and regulatory feasibility of on-site waste treatment for deep burn reactors using the Archimedes Filter, and its merits versus similar concepts such as the ALMR with Pyro-processing [5]. If favorable, an on-site closed nuclear cycle could be developed in time to contribute to the goal of virtually eliminating carbon emissions in California by 2050 . TeraPower estimates that it could market TWR's in about 10 years. Early deployment of TWR's with Archimedes Filters, followed by fusion/ fission hybrids, could eliminate all coal plants supplying electricity to California. Indeed, all coal plants in the US could be eliminated by deep burn reactors fueled hundreds of years by existing depleted uranium as fuel, with a progressive improvement in nuclear power from advanced fission reactors to fusion-fission hybrids to pure fusion reactors. A clear path toward an environmentally friendly closed nuclear cycle could help revive work on the Archimedes Filter and motivate an invigorated advanced fission reactor effort, in parallel with impending attempts to achieve fusion ignition in NIF beginning in 2010, and extended fusion burn in ITER before 2020.

Acknowledgments We thank John Gilleland at TeraPower, Joe Farmer and Jeff Latkowski at LLNL and our colleague Ehud Greenspan for many helpful discussions, data and ideas that contributed to this paper.

Open Access This article is distributed under the terms of the Creative Commons Attribution Noncommercial License which permits any noncommercial use, distribution, and reproduction in any medium, provided the original author(s) and source are credited.

\section{Appendix}

In this "Appendix", we give example non-optimized parameters for a Modified Archimedes Filter for the scenario of Fig. 2, aimed at recycling certain fission products to produce Class $\mathrm{C}$ waste suitable for shallow burial. The required Archimedes modification is one allowing the separation of different masses.

An Archimedes Filter is an Aston Mass Spectrometer adapted to a plasma target. The filter consists of a cylindrical steel vessel with a magnetic field $B$ along the axis, and a radial electric field produced by an array of circular electrodes at each end. Material to be processed is injected radially at the middle of the vessel, in a form that can be ionized by R. F. power. Heavier ions are collected radially while lighter ions flow toward each end of the cylinder. For one stage, the light ions are collected at the ends. A multistage unit would consist of an array of radial collectors along a device with parameters adjusted to collect successively smaller masses along its length.

Which ions are collected radially is determined by the conservation of angular momentum giving azimuthal velocity $v_{\theta}=\left(\frac{e B}{2 m r}\right)\left(r^{2}-r_{\mathrm{o}}^{2}\right)$ for an ion of charge $e$ and mass $m$ created by an ionization event at a radius $r=r_{\mathrm{o}}$ in the presence of an electric field $E \propto r$. Ions can be collected at $r=R$ if the azimuthal kinetic energy is less than the potential difference between the collection radius $R$ and $r_{\mathrm{o}}$, giving (MKS units):

$\frac{8 m V}{e B^{2}}>\left(R^{2}-r_{\mathrm{o}}^{2}\right) \frac{a^{2}}{R^{2}}$

where $0<r<a$ is the dimension of the electrode array with voltage $V$ and $a<R$. Ideally, applying Eq. (1) with $r_{\mathrm{o}}=0$ guarantees that all ions with mass $\geq m$ are collected radially no matter where they become ionized. Let this threshold mass be $A_{H}$ (heavy) in atomic mass units. Setting $r_{\mathrm{o}}=a$ and reversing the inequality denies access at $R$ to all ions with mass $<m$, even those ionized near the plasma edge. Let this threshold be $A_{L}$ (light). Both the heavy and light thresholds are achieved simultaneously if:

$\frac{a^{2}}{A_{H}}=\frac{8 V m_{p}}{e B^{2}}=\left(1-\frac{a^{2}}{R^{2}}\right) \frac{a^{2}}{A_{L}}$

with proton mass $m_{\mathrm{p}}$. Applying Eq. (2) at any location along the Filter will guarantee that all ions with $A \geq A_{H}$ are collected, none passing onto the next section. No ions with $A \leq A_{L}$ are collected, all being passed along to the next stage. Masses between these limits are only partially collected. Non-ideal effects including controlling plasma temperature to maintain singly-ionized states yielded $95 \%$ efficiency in collecting heavy ions in the Archimedes Demonstration Facility.

The main requirements on the Modified Archimedes Filter are:

(1) To separate all actinides (say $A_{H}>200$ ) for recycling. About 4 passes through the Archimedes Filter is required as noted above.

(2) To separate ${ }^{90} \mathrm{Sr}$ and ${ }^{137} \mathrm{Cs}$ for cool down to Class C standards on site before sending these into the $1 \mathrm{~m}^{3} /$ year waste stream package. Currently it is not necessary to separate ${ }^{135} \mathrm{Cs}$, with activity levels low enough to qualify as Class $\mathrm{C}$ without recycle.

(3) To separate ${ }^{94} \mathrm{Nb},{ }^{99} \mathrm{Tc}$ and ${ }^{126} \mathrm{Sn}$ in batches to be sent through AVLIS for isotopic separation and recycle, the rest going directly to the waste stream. About 3 passes through the Archimedes Filter would be required for Class $C$.

(4) All the rest to be separated and sent directly to the waste stream.

To accomplish this, we require a Filter with stages in which $A_{H}<200,137,126,99,94,90$ together with appropriate $A_{L}$ 's. Let us assume that, as in the original Filter, plasma conductivity propagates a potential profile imposed by circular electrodes at the ends all along the 
Table 4 Conceptual design parameters for a modified Archimedes filter

\begin{tabular}{|c|c|c|c|c|c|c|c|}
\hline$A_{L}$ & $A_{H}$ & Isotope & $B / B_{\mathrm{o}}$ & $a(\mathrm{~m})$ & $R(\mathrm{~m})$ & Mass (kg) & Disposition \\
\hline 170 & 200 & Actinides & 1 & 0.2 & 0.76 & 100 & Recycle \\
\hline 133 & 140 & None & 0.7 & 0.24 & 1.2 & 245 & To waste \\
\hline 128 & 133 & ${ }^{137} \mathrm{Cs}$ & 0.66 & 0.25 & 1.25 & 216 & Cool down $\rightarrow$ waste \\
\hline 110 & 120 & ${ }^{126} \mathrm{Sn}$ & 0.6 & 0.26 & 0.9 & 14 & AVLIS $\rightarrow$ waste $\rightarrow$ recycle ${ }^{126} \mathrm{Sn}$ \\
\hline 100 & 105 & None & 0.52 & 0.28 & 1.27 & 68 & To waste \\
\hline 91 & 95 & ${ }^{94} \mathrm{Nb},{ }^{99} \mathrm{Tc}$ & 0.47 & 0.29 & 1.45 & 241 & AVLIS $\rightarrow$ waste $\rightarrow$ recycle ${ }^{99} \mathrm{Tc},{ }^{94} \mathrm{Nb}$ \\
\hline$A \leq 90$ & ${ }^{90} \mathrm{Sr}$ & To the ends & & & & $\begin{array}{l}116 \\
1,000\end{array}$ & Cool down $\rightarrow$ waste \\
\hline \multicolumn{4}{|c|}{ Direct to waste } & & & 313 & \\
\hline \multicolumn{4}{|c|}{ To waste after cool down } & & & 332 & \\
\hline \multicolumn{4}{|c|}{ To waste through AVLIS } & & & 225 & \\
\hline \multicolumn{4}{|c|}{ To waste } & & & 870 & \\
\hline \multicolumn{4}{|c|}{ Recycle through AVLIS: ${ }^{94} \mathrm{Nb},{ }^{99} \mathrm{Tc},{ }^{126} \mathrm{Sn}$} & & & 30 (mostly $\left.{ }^{99} \mathrm{Tc}\right)$ & \\
\hline \multicolumn{4}{|c|}{ Direct to recycle (actinides) } & & & 100 & \\
\hline \multicolumn{4}{|c|}{ Recycle } & & & 130 & \\
\hline \multicolumn{4}{|l|}{ Total } & & & 1,000 & \\
\hline
\end{tabular}

As in Tables 1 and 4 omits throughput of unburned uranium, which influences cost as discussed in the text

field lines. Then we can design for a fixed $V$, of order 1,000 volts as in the original Filter. The potential is $\Phi(r)=V\left(1-r^{2} / a^{2}\right)$ varying over $0<r<a$ as noted above, while collection occurs at a wall radius $R>a$. Let us also assume that injection and RF ionization can be controlled so that plasma is created only within $0<r<a$ so that all pickup occurs at $r_{0} \leq a$ in Eq. (1). By Eq. (2), collecting different mass batches is accomplished at fixed $V$ by varying $a$ and $B$ along the length with $a=a_{\mathrm{o}}$ and $B=B_{\mathrm{o}}$ at the center region where actinides are collected and $a^{2} B=a_{\mathrm{o}}^{2} B_{\mathrm{o}}$ thereafter to conform to flow of plasma along magnetic field lines. The net result is a cylinder with increasing radius away from the waste injection point at the middle, with coils with currents adjusted to vary $B$ from $B_{\mathrm{o}}$ at the center to roughly (90/200) $B_{\mathrm{o}}$ at each end, and $a_{\mathrm{o}}$ and $R_{\mathrm{O}}$ in ratio $a_{\mathrm{o}} / R_{\mathrm{O}}=0.4$ at the center varying to $a / R=0.2$ at the ends. The center $a_{\mathrm{o}}$ could be smaller than the original design, say $0.2 \mathrm{~m}$.

The main new physics feature of this multi-stage design is some axial acceleration of the ions born in a non-uniform magnetic field, giving the ion an axial velocity $v_{z}$ given by:

$\frac{v_{z}}{v_{r}} \approx \frac{2\left(R-r_{\mathrm{o}}\right)}{L}$

Then, in the time $\left(R-r_{o}\right) / v_{r}$ required for radial transport to the wall, the maximum axial spread $\mathrm{d}$ of the strike point due to $v_{z}$ is:

$d=2 \frac{v_{z}}{v_{r}}\left(R-r_{\mathrm{o}}\right)<2 R \frac{R}{L}$
For $L=10 \mathrm{~m}$ and $R \approx 1 \mathrm{~m}$, this appears to be a small correction, as could be confirmed by codes to calculate ion collection developed at Archimedes Technology.

This example design is not optimized and is intended only the show the potential versatility of a Modified Archimedes Filter for waste management. For example, if regulations for ${ }^{129} \mathrm{I}$ or ${ }^{135} \mathrm{Cs}$ become more restrictive, a simple change in $A_{L}$ 's and $A_{H}$ 's could collect these isotopes with ${ }^{126} \mathrm{Sn}$ for recycle through AVLIS. Also, the listed AVLIS throughput, though manageable, is about twice that suggested in the text based on proliferation concerns. And a correct design would be based on an actual inventory for a TWR or LIFE operated in steady state with recycle.

Misuse of the Modified Archimedes Filter to separate the ${ }^{239} \mathrm{Pu}$ isotope is foiled, even for the ideal limit of Eq. (2). The governing quantity is $a / R$. Near the center where $a / R=0.4$, collecting ${ }^{239} \mathrm{Pu}$ would also collect all $A>\left(1-0.4^{2}\right)$ $239=201$. Using the lower values of $a / R$ further out requires moving the injection system-not a small task —and in any case would collect all $A>\left(1-(0.2)^{2}\right) 239=229$, hence all of the unburned ${ }^{238} \mathrm{U}$. Even ideally, separating ${ }^{239} \mathrm{Pu}$ from ${ }^{238} \mathrm{U}$ requires $a / R=\sqrt{1-238 / 239}=0.06$. Actual experience at Archimedes Technology failed to produce a practical separator for such close-spaced masses.

A Modified Archimedes Demonstration Facility could be carried out at full scale, at a cost $\approx \$ 100 \mathrm{M}$ based on costs of the original Demonstration Facility with a 
throughput of 0.25 ton/day or 90 tons/year. The Modified Filter would be perhaps twice the length, at an increased cost offset by a lower throughput requiring much less RF power (only a few MW) (Table 4).

\section{References}

1. J.C. Farmer, J.A. Blink, H.F. Shaw, LIFE vs. LWR: end of the fuel cycle. LLNL-TR-408781, Nov. 17, 2008

2. J. Ahn, M. Cheon, E. Greenspan, Effects of accelerator-driven transmutation system on radiotoxicity of high-level radioactive wastes. Nucl. Technol. 158, 409-430 (2007)

3. J. Ahn, M. Cheon, Linear programming approach for optimization of radionuclde loading in vitrified HLW. Nucl. Technol. 156, 303 (2006)
4. Data from Bechtel SAI, provided by J. Farmer, LLNL

5. W.J. Hannum, G.E. Marsh, G.S. Stanford, Smarter use of nuclear waste. Sci. Am. Dec. 2005

6. J.P. Holdren et al., Exploring the competitive potential of magnetic fusion energy: the interaction of economics with safety and environmental characteristics. Fusion Tech. 13, 7 (1988)

7. S. Fetter, E.T. Cheng, F.M. Mann, Long-term radioactivity in fusion reactors. Fusion Eng. Des. 6, 123 (1988)

8. DOE Manifest Information Management System, http://mims.apps. em.doe.gov

9. Jeff Latkowski, private communication

10. James I. Davis, private communication

11. R.F. Post, R.S. Lowder, L.A. Schwager, W.L. Barr, B.E. Warner, Novel wave/ion beam interaction approach to Isotope separation. LLNL, UCRL-JC-110971 (1994)

12. Scott Nagley, private communication 